\title{
El pentecostalismo chileno en los espacios Aymara y Quechua de Bolivia (1938-1960)*
}

\section{Chilean Pentecostalism in the Aymara and Quechua Spaces of Bolivia (1938-1960)}

\author{
Miguel Ángel Mansilla \\ (D) http://orcid.org/0000-0001-5684-0787 \\ Instituto de Estudios Internacionales (INTE) \\ Universidad Arturo Prat, Chile \\ mansilla.miguel@gmail.com
}

\section{Luis Orellana Urtubia}

(D) http://orcid.org/0000-0001-7411-2126

Instituto de Estudios Internacionales (INTE)

Universidad Arturo Prat, Chile

luis_ubl@yahoo.com

\section{Nicolás Panotto}

\section{(D) https://orcid.org/0000-0002-0513-7175}

Instituto de Estudios Internacionales (INTE)

Universidad Arturo Prat, Chile

nicolaspanotto@gmail.com

* Este artículo es resultado del proyecto Fondecyt Regular núm. 1180924, "La fe mueve fronteras”. Además, agradecemos a la VRII de la Universidad Arturo Prat, por el financiamiento para la asistencia al Congreso de FIFrem realizada en Creel, Bocoyna, Chihuahua, México, en junio de 2019.

cómo citar: Mansilla, M. Á., Orellana Urtubia, L. y Panotto, N. (2020). El pentecostalismo chileno en los espacios Aymara y Quechua de Bolivia (1938-1960). Secuencia (107), e1746. DoI: https://doi. org/10.18234/secuencia.v0i107.1746 
Resumen: Este artículo tiene por objetivo analizar la génesis de la relación del pentecostalismo chileno con la cultura Andina, especialmente la boliviana, como opción religiosa válida en el contexto cultural. Teóricamente nos sustentamos en Clifford Geertz, para quien la religión incluye la tradición objetiva y subjetiva como también una visión simbólica y ostensiva de las creencias. Metodológicamente, se utiliza como fuente de información la revista Fuego de Pentecostés, donde aparecen reportes de misioneros pentecostales chilenos en Bolivia. Los resultados de la investigación son: la misión como ideología civilizatoria, la inclusión de lengua indígena, enfermedad, sanidad, sueños, visiones, construcción de redes misionales, ritos y ceremonias.

Palabras clave: pentecostalismo; Bolivia; Aymara; Chile.

Abstract: This article seeks to analyze the genesis of the relationship between Chilean Pentecostalism and Andean culture, particularly Bolivian culture, as a valid religious option in the cultural context. Theoretically, we rely on Clifford Geertz, for whom religion includes the objective and subjective tradition as well as a symbolic and ostensive view of beliefs. Methodologically, Fuego de Pentecostés journal, in which reports of chilean pentecostal missionaries in Bolivia are published, is used as an information source. The results of the research are the mission as a civilizing ideology, the inclusion of indigenous language, disease, health, dreams, visions, the construction of mission networks, rites and ceremonies.

Keywords: pentecostalism; Bolivia; Aymara; Chile.

Recibido: 21 de mayo de 2019 Aceptado: 31 de julio de 2019

Publicado: 11 de mayo de 2020 


\section{INTRODUCCIÓN}

T as investigaciones antropológicas sobre el pentecostalismo comenzaron La mediados de la década de 1960, ${ }^{1}$ en términos comparativos entre Chile-Brasil y Chile-Perú. Nos referimos específicamente al trabajo del antropólogo alemán-estadunidense Emilio Willems, titulado Followers of the new faith: Culture change and the rise of protestantism in Brazil and Chile, publicado en 1967. El mismo año el holandés Juan Kessler publica su trabajo A study of the older protestant missions and churches in Peru and Chile, y un año después vino el libro El refugio de las masas, del sociólogo suizo Christian Lalive d'Epinay. Estos tres autores europeos aludieron a la relación del pentecostalismo y el protestantismo con la cultura mapuche e hicieron breves alusiones en la misma dirección con la cultura aymara, especialmente Kessler, al hacer referencias a las relaciones entre los adventistas y la cultura aymara en Perú y Bolivia.

En una segunda etapa (años setenta y ochenta) están las investigaciones sobre pentecostalismo y cultura andina, particularmente con la aymara. Estas indagaciones siguieron la tónica general en América Latina centradas en la teoría de la sospecha y conspiración, donde se ve al pentecostalismo como una arremetida de la incidencia imperialista de Estado Unidos en la región. En el caso andino chileno, el pentecostalismo fue un instrumento de la dictadura militar. Posturas que no fueron superadas en los ochenta, evidenciando importantes limitaciones epistémicas, teóricas y metodológicas. Una tendencia clara fue el refugiarse en posiciones teóricas descontextualizadas, considerando la existencia de una insuperable realidad religiosa en la cultura aymara. Además, el conflicto fue considerado como una realidad maligna y el sujeto indígena una víctima. En términos metodológicos las investigaciones también fueron limitantes, al someterse a espacios reducidos, sin permitir comparaciones regionales y continentales, al concentrar los estudios en algunos pueblos (Cariquima, Colchane, Camiña, Putre, etc.), sin considerar estos como fronterizos. En lo teórico se utilizaron definiciones de cultura y religión muy reduccionistas. Por ejemplo, para la definición de religión se recurrió a las nociones de secta/iglesia. El debate quedó atrapado epistemológicamente en una concepción del indígena como víctima de las fuerzas so-

1 Walter Hollenweger (1976), teólogo suizo, publica en 1966 su tesis doctoral, Manual del movimiento pentecostal considerada como el estudio pionero en los estudios del pentecostalismo mundial, y después su conocido libro: Los pentecostales. 
ciales y procesos históricos (Hernández, 1994). En realidad, si realizamos un abordaje epistémico-teórico del culturalismo de Geertz (2003), por ejemplo, podemos notar que los creyentes indígenas nunca han sido seres pasivos de los mensajes religiosos (Garma y Embriz, 1994). Una tercera etapa, aquellas nuevas investigaciones realizadas en el periodo posdictadura (Guerrero, 1994; Tudela, 1993) y en un contexto de globalización que visibiliza la migración y la movilidad transfronteriza, muestran nuevos abordajes (Mansilla, Muñoz y Orellana, 2014; Mansilla, Muñoz y Piñones, 2016; Mansilla y Muñoz, 2017a, 2017b; Mansilla, Piñones y Liberona, 2018; Piñones, Mansilla y Muñoz, 2016; Piñones, Muñoz y Mansilla, 2018) de una realidad étnico-religiosa muy distinta de la descrita en la década de 1980.

No obstante, no hay trabajos realizados durante la década de 1960 hacia atrás, considerando que el pentecostalismo llegó al altiplano boliviano en el año 1938, y en 1957 en el altiplano chileno. Por otro lado, tampoco se registran investigaciones relacionadas con pentecostalismo y cultura andina desde la década de 1960 hacia atrás. No hay que entender la antropología sólo como una ciencia social contemporánea, limitando lo etnográfico a la observación participante del investigador o a lo más lejos la realización de entrevistas a los sujetos de investigación, sino también, considerando a los archivos históricos como material antropológico. En esta dirección, algunos autores consideran que "la antropología histórica como etnohistoria. El etnohistoriador es el antropólogo que utiliza documentos escritos, esto es, las mismas fuentes que el historiador, pero se diferencia en que su tarea consiste en convertir un material esencialmente histórico en material etnográfico" (Martínez, 2006, p. 4).

En consecuencia, nuestro trabajo pretende, precisamente, mostrar que existen muestras de estos análisis en muchos documentos históricos, los cuales a veces no son considerados por las ciencias sociales como material de análisis debido a su configuración. Esta investigación no se trata de un trabajo etnohistórico ni de historia de las religiones (o del pentecostalismo), sino más bien es un enfoque antropológico, cuyo objetivo es describir la génesis de la relación del pentecostalismo con la cultura andina, para comprender el proceso de ser una religión extranjera y extraña a un contexto andino, especialmente el boliviano, a una opción religiosa válida en el contexto cultural. Teóricamente, nos sustentamos en la concepción geertziana de la religión, para quien dicho campo se trata de 1) un sistema de símbolos que obra para, 2) establecer vigorosos, penetrantes y duraderos estados anímicos y motivaciones entre los hombres; 3) formula concepciones de un orden general de 
existencia; 4) reviste estas concepciones con un aura de efectividad tal que, 5) los estados anímicos y motivaciones parezcan de un realismo único (Geertz, 2003 , p. 89). Dicha propuesta parece más apropiada donde lo teórico incluye la tradición objetiva y subjetiva de la religión como también una visión simbólica y ostensiva de las creencias; por último, concibe lo religioso (en consonancia con Weber y Berger) como teodiceas, es decir, como respuestas de sentido frente a los dilemas existenciales del ser humano, tanto del dolor (enfermedades, desempleos) como el dilema del mal (injusticias).

Metodológicamente, utilizaremos como fuente la revista Fuego de Pentecostés, donde aparecen reportes de misioneros pentecostales chilenos, y en los cuales se evidencia su apreciación de los aymaras y quechuas, esencialmente sobre su relación con el evangelio, la asistencia al templo o la conversión. Su estudio nos ayudará, en forma parcial, a responder algunas preguntas: ¿cómo fue la relación del pentecostalismo chileno con la cultura aymara boliviana en sus inicios?, ¿qué estrategia o recursos sociales y simbólicos empleó el pentecostalismo para ganar conversos indígenas?, ¿qué nos dicen las declaraciones misioneras pentecostales sobre la cultura andina? Si no existieran esos retazos de información escrita, "no habría ninguna posibilidad de que estos individuos, con su vida y sus desgracias, surgiesen de la sombra en lugar de tantos otros que permanecen en ella" (Foucault, 1996, p. 83), es como "si no hubiese existido, pero sobrevive gracias a la colisión con el poder que no ha querido aniquilarla o al menos borrarla de un plumazo" (p. 83). En resumen, el estudio de estos archivos, pese a mantener una visión institucional del sujeto, nos permitirán acceder a importantes fragmentos de documentación, a partir de "las declaraciones, las parcialidades tácticas, las mentiras impuestas que suponen los juegos del poder y las relaciones de poder" que se reflejan entre las líneas de su redacción (Foucault, 1996, p. 81).

\section{LA MISIÓN PENTECOSTAL COMO IDEOLOGÍA CIVILIZATORIA}

Grupos religiosos como los pentecostales, que sustentan su legitimidad en la cantidad de fieles, buscan acercar esta oferta simbólica a espacios que a ellos les parece coherentes, como los indígenas. Quienes encuentran y aceptan nuevos símbolos religiosos culturalmente afines lo hacen porque, como destaca Geertz (2003) “estos suministran una garantía cósmica no sólo de su 
capacidad de comprender el mundo sino también, de dar precisión a los sentimientos y emociones que experimenta" (p. 101). Como toda misión religiosa, los pentecostales buscan la legitimación política nacional y/o local a través de su quehacer misional: "Llegamos a Cochabamba el 10 de diciembre de 1938 y el 29 de enero [de 1939], inauguramos nuestro primer local en este país [...] fuimos a presentarnos a la Autoridad para los cual nos hicimos acompañar del Cónsul de Chile. El señor Alcalde [...] nos entregó la ciudad en nuestras manos, con la sola excepción de la Plaza 14 de Septiembre."2

Esta cita resulta llamativa porque en Bolivia no existía separación entre Iglesia y Estado, pero sí había libertad religiosa, excepto en la plaza mayor, donde se encontraba la catedral católica.

La prédica en la calle ha sido utilizada como la principal estrategia de visibilización pública por los pentecostales chilenos. Los primeros misioneros pentecostales trasladan esta práctica de evangelización a Bolivia, pero con escasos resultados, pues como destaca Geertz (2003, p. 122), el papel de la religión difiere histórica, social y culturalmente. Entre las grandes dificultades, encontramos que dicha estrategia de prédica conlleva una visión individualista de lo religioso, mientras que Bolivia era, y es, un país mayoritariamente indígena en donde las relaciones comunitarias están por sobre el individuo. Estas limitaciones se hacen aún más patentes cuando se trata del pentecostalismo de la época, al ser considerada una religión extranjera y extraña para la comunidad andina. Dado que el pentecostalismo en Chile era una religión de los pobres, al no poder convertir a los indígenas bolivianos con rapidez, entonces los líderes buscaron adecuarse a la cultura local y llegar a los más pobres desamparados: en este caso a los enfermos.

Esta inculturación instrumental de los pentecostales a la cultura local implicaba ofrecer los recursos simbólicos y sociales que las personas pudieran necesitar; en tanto, "fusionaba el ethos pentecostal con la cosmovisión indígena, y de este modo, recurrir a los símbolos de dicha cosmovisión, para ofertar sanidad según las necesidades individuales, familiares y comunitarias" (Geertz, 2003, p. 122). Como señalamos antes, el pentecostalismo era, para los bolivianos, una religión extranjera, extraña y excluyente, pero aún era posible constituirse en una opción de sentido: "Salimos a la calle y predicamos al aire libre y al entonar nuestro primer himno la gente corría por las calles para oírnos [...] El cántico de los Anunciadores de las Buenas Nuevas

\footnotetext{
2 Fuego de Pentecostés, 1939, núm. 127, p. 8.
} 
rompía el silencio de las tinieblas y daba oportunidad a las almas perdidas para encontrar la luz y el gozo de salvación por la fe en Cristo."

El canto también es un recurso emotivo que transmite, canaliza emociones, sentimientos y forma parte del proceso terapéutico. El relato desprende varias metáforas que los misioneros pentecostales chilenos realizan en la construcción del otro, en este caso el boliviano, y el nosotros, evangélicos chilenos. En tanto el ethos, según Geertz (2003), "es el tono, el carácter y la calidad de vida, estilo moral y estético y la disposición de ánimo" (p. 121). Por lo tanto, el pentecostalismo busca ese encuentro entre el ethos pentecostal/ andino y la cosmovisión pentecostal/andina. Y, en tanto, en el pentecostalismo concibe García (2009) "el mundo como un escenario de un gran combate, de una guerra crucial entre el bien y el mal, entre la luz y las tinieblas" (p. 62), traslada esta lucha al ámbito de la cultura $y$, por lo tanto, los otros eran representados como el "silencio de las tinieblas", las "almas perdidas" o los "frutos", mientras que el nosotros como "anunciadores de buenas nuevas", "sonido de la luz" y "sembradores". Habiendo identificado el ethos andino como lo oscuro, se necesitaba con urgencia convertir a nativos para mostrar una opción religiosa "razonable al mostrárselo como representante de un estilo de vida idealmente adaptado al estado de cosas" (Geertz, 2003, p. 89).

Los pentecostales comienzan a buscar el encuentro con la cosmovisión andina, con el fin de situarse y legitimarse como una religión plausible para los oyentes indígenas. Pero, sin antes enfrentar nuevas resistencias,

Estamos trabajando en la predicación del evangelio con muchas dificultades. Aquí la gente es muy rebelde, el martes salimos a predicar a una plaza, nos apedrearon, y sucedió que ellos tienen por ahí un Cristo que llaman de la esperanza y se quemó o ellos le prendieron fuego y nos echaron a nosotros la culpa. Nos atizaron a la policía. Así estamos predicando al Señor, con calumnias. ${ }^{4}$

Al canalizar los pentecostales la violencia religiosa hacia la autovictimización y una especie de "mesianismo", elementos que tomarán como parte de su ethos y de ese modo obtener la atención entre los lugareños. Asimismo, la violencia y la persecución son tomadas como recursos simbólicos que fortalecen las expectativas del proyecto misionero y que posteriormente adorna-

${ }^{3}$ Fuego de Pentecostés, 1939, núm. 127, p. 8.

${ }^{4}$ Fuego de Pentecostés, 1957, núm. 335, p. 16. 
rán los mitos fundacionales. Lo anterior, permite que, en unos pocos meses, los pentecostales envían nuevos misioneros chilenos a Bolivia. Ahora tienen misioneros en Oruro y Cochabamba. ${ }^{5}$ Pero se continúa destacando la persecución, en vez de describir otras experiencias:

Continuamos los trabajos al aire libre, eso sí que con mucha persecución. Una noche se nos levantó un grupo de hombres y mujeres y nos corrieron hacia el local y una chola le dio unos cuantos puñetes al hermano Irigoyen [...] Otra tarde se levantó amenazante otro grupo de hombres y mujeres y tuvo que intervenir un agente de policía. Un Domingo un grupo de unas cuantas cholas nos insultaron mucho en Quechua. ${ }^{6}$

Se integra así la retórica de la tenaz resistencia, pero a su vez añadida como parte del ethos misionero. Pese a la adversidad que relatan los misioneros en Bolivia, esta oposición se comprende como una contienda por sus creencias religiosas y no por ser chilenos, no obstante, para los relatores, eso no importa: sólo interesa resaltar el imaginario sufriente del misionero. Los misioneros recurren al conocido imaginario del cholismo para referirse a las mujeres indígenas bolivianas (aymara y quechua), que supone la determinación de una barrera racial donde ellos se autoconsideraban blancos y, por ende, con cierto estatus de superioridad social. Por consiguiente, el sentido de evangelizar implicaba también civilizar. La ideología misionera trata, entonces, según Alves (1979) "en todos los lugares donde el movimiento misionero se implantó, los nativos aprenden que su cultura es pagana. Por tanto, la conversión es el esfuerzo de romper con ella" (p. 237), y la ideología misionera también se hace parte del ethos civilizatorio, en cuanto el ethos "se trata de la actitud subyacente que un grupo tiene ante sí mismo y ante el mundo que la vida refleja" (Geertz, 2003, p. 121).

El sentimiento de hostigamiento es resignificado, García (2009) destaca que "la persecución [es concebida] como una estrategia de la providencia que causa la mayor difusión del mensaje” (p. 74). Así lo afirman los misioneros: "La persecución ha servido para ver la mano del Señor en nuestra defensa, porque Dios ha usado de entre ellos mismos para defendernos. También ha servido para tener una buena concurrencia en nuestras reuniones [...] Con

${ }^{5}$ Fuego de Pentecostés, 1939, núm. 130, p. 8.

${ }^{6}$ Fuego de Pentecostés, 1939, núm. 127, p. 8. 
todo vemos que para el obrero cristiano en Bolivia la misión se hace difícil porque la mayor parte de la gente habla el quechua y el aimará."

Como toda ideología misionera, no ve el bien en los "misionados". No obstante, uno de los problemas que captan los misioneros es un problema cultural, algo que ni siquiera el catolicismo logró sortear: el indígena. ¿Qué hacer?, ipredicarles en español o en su idioma nativo?, ipermitirles el liderazgo o tratarlos con paternalismo? Los pentecostales chilenos esto lo resuelven al integrar al indígena al liderazgo y dar paso a la prédica en su idioma vernácula. Lo significativo fue que los pentecostales no centraron el origen de la violencia y la persecución en las personas, sino lo asumen como un símbolo metafísico que respondía a fuerzas espirituales hostiles: "el diablo también está en Bolivia y ha querido interrumpir nuestra labor; pero todo ha servido para que el Evangelio llegara también a las autoridades, los que después sólo se ha preocupado de nosotros para protegernos". ${ }^{8}$

Durante los primeros diez años, el pentecostalismo chileno en Bolivia fructificó muy poco, tanto en Cochabamba como en Oruro:

En Cochabamba [...] sólo quedan hermanos dispersos. Hacía tres meses que se reunían tres o cuatro para ayunar y leer la palabra de Dios en el día del Señor. Al anuncio de nuestra visita y buscando a otros, tuvimos reuniones todas las noches [...] Nos contaron con toda franqueza, sus odiseas, al pretender con el espíritu que primeramente habían recibido comulgar con denominaciones que asiduamente les invitaban a sus congregaciones. ${ }^{9}$

Sólo queda un ministro local, como es el pastor Salguero, quien es el único que predica en quechua y viaja, a lo menos, una vez al año a Chile, pidiendo el envío de misioneros. Este vive en La Paz donde trabaja como mecánico y en la misma casa realiza cultos y congrega algunos pocos conversos. ${ }^{10}$ Sin embargo, dos décadas más tarde de su llegada, el pentecostalismo comienza a despegar en Bolivia. Uno de los grandes estímulos fueron los efectos de la revolución de 1952, especialmente en lo que refiere a la transformación en la cosmovisión social sobre los indígenas, quienes, además de su

\footnotetext{
${ }^{7}$ Fuego de Pentecostés, 1939, núm. 127, p. 8.

${ }^{8}$ Fuego de Pentecostés, 1940, núm. 145, p. 6.

${ }^{9}$ Fuego de Pentecostés, 1951, núm. 267, pp. 12-13.

10 Fuego de Pentecostés, 1951, núm. 267, pp.12-13.
} 
ethos sociocultural particular, comienzan a ser reconocidos desde un sentido más estrictamente de clase, como campesinos que como indígenas. Es decir, se le niega su diferenciación étnica, se le niega su cultura. Si los misioneros pentecostales antes eran étnicamente distintos, ahora son socialmente similares: ambos son pobres. Por lo tanto, el discurso religioso pentecostal se hace más coherente con la cosmovisión andina, en tanto la cosmovisión "se hace emocionalmente convincente al presentársela como una imagen de un estado de cosas peculiarmente bien dispuesto para acomodarse a tal estilo de vida" (Geertz, 2003, p. 89).

El protestantismo siempre fue rechazado por ser la religión del blanco, del opresor, del extranjero; ahora el pentecostalismo viene a ser la religión del moreno, del explotado y del extraño. Pero algo que irá cambiando con la conversión de los aymaras y quechuas es que comenzarán a predicar en su idioma vernáculo y, por lo tanto, dejarán de ser los extraños. Se encontrarán así la hermandad indígena (los aymaras se dicen hermanos) con la religiosa (de la misma manera, los pentecostales se dicen hermanos). De este modo el liderazgo indígena que fue asumiendo las misiones pentecostales en Bolivia, su oferta de comunidad y sanidad adquieren sentido porque son anunciadas según el universo lingüístico y simbólico andino a través de la lengua indígena junto a sus sueños y visiones. El último paso será que, al reconocer estos pueblos a los pentecostales como parte de la hermandad, entra en acción la solidaridad y la reciprocidad andina, la donación de terrenos y materiales para la construcción de templos.

\section{LA INCLUSIÓN DE LENGUA INDÍGENA EN LOS CULTOS PENTECOSTALES}

Lentamente el pentecostalismo se va arraigando en espacios indígenas, al incorporar líderes de las mismas comunidades para que presidan los locales de predicación, iniciando grados de autonomía y dinámicas, en tanto sus contenidos también se van configurando desde las cosmovisiones indígenas. Esto lo hace distinto a otras iglesias protestantes, e inclusive pentecostales que trabajaban en ciudades y otras poblaciones (Tamagno, 2007; Terán, 2005). El pentecostalismo chileno en Bolivia tempranamente se interesa por "la cuestión religiosa indígena"; no obstante, no fue algo inédito en la zona, pues los protestantes adventistas habían iniciado un trabajo similar, con predicadores 
itinerantes entre Puno y La Paz ya a comienzos del siglo xx, por el año 1911 (Sthal, 1920; Valenzuela, 2000).

Pero ahora serán los misioneros chilenos quienes emplearán recursos y estrategias que tendrán éxito en Bolivia: "Bolivia es un país muy raro en sus costumbres, dialectos, etc. Todos recordarán que mi hermano Irigoyen cantaba algunos himnos en Quechua, pero hoy no solamente canta, sino que también toda su predicación en calles, plazas y mercados, lo hace en Quechua."11 El uso del canto en idioma indígena, que históricamente fue despreciado por las misiones e iglesias cristianas, llama la atención de los indígenas. Los cánticos asumen la misma dimensión que ya Geertz (2003) aplicó a otros casos, "el simbolismo del cántico se concentra en el problema del sufrimiento humano e intenta afrontarlo colocándolo en un contexto con sentido" (p. 101). De forma antagónica, el protestantismo misionero liberal afirmaba que las lenguas indígenas iban a desaparecer y por tanto no era necesario enseñar el evangelio a las comunidades en su lengua nativa ya que ni siquiera sabían leer o escribir en su propia lengua; por ello había que instruirlos en español (Piedra, 2002). Desde un camino contrario, los protestantes misioneros y pentecostales emplearán con éxito un modelo de contextualización y participación nativa donde el idioma es el principal acercamiento a la cultura.

La lengua es la principal forma de interpretar y transmitir los símbolos sagrados, pues estos "tienen la función de sintetizar el ethos de un pueblo y su cosmovisión" (Geertz, 2003, p. 89). Los misioneros pentecostales inician el aprendizaje del idioma para predicar, pero sobre todo para evangelizar, discipular y constituir un líder local,

El quechua y el aymara son los dialectos que se hablan en general [...] Hoy día hay numerosos grupos "evangélicos" que van minando el poder absoluto de la religión de siglos en Bolivia. Estos sectores no comulgan con prácticas pentecostales y se caracterizan por un fuerte espíritu de controversia. Pero la continua propaganda escrita y oral está preparando el ambiente para la neta obra de Dios. ${ }^{12}$

De igual modo el pentecostalismo, como en otras realidades indígenas, no predica en la tabula rasa, sino que aborda las creencias católicas popula-

${ }^{11}$ Fuego de Pentecostés, 1940, núm. 145, p. 6.

12 Fuego de Pentecostés, 1951, núm. 267, pp. 12-13. 
res, con el objetivo de hacer del protestantismo un adversario y así construir un espacio de disputa de sentido con el catolicismo como enemigo religioso. De este modo, se diferencia de los grupos religiosos anteriores al valorar la lengua vernácula: "el país es minero por excelencia y ahora está en un furor por aumentar su producción de sus inestimables depósitos de petróleo. Es un país del futuro, 'Caika, niyquichej; Ñahuisniyquichejtaokariychej, campostajkahuaypajka, imaraicuchusyurajllañarutuypajkacashancu”" [Jn. 4. 35]. El texto en quechua dice "alzad vuestros ojos". ${ }^{13}$ Dado que "los símbolos religiosos apuntan no sólo hacia la existencia del bien sino también hacia la del mal y hacia el conflicto entre ambos" (Geertz, 2003, p. 121), por lo tanto, se interpreta la existencia del mal, tanto externa como internamente al individuo, en la figura del diablo. De la misma manera, el pentecostalismo es una religión que polemiza, incluso con el protestantismo, al responsabilizarlo de captar a los creyentes ganados por los pentecostales chilenos,

En nuestra visita tocamos tres ciudades; primero Oruro, donde estuvo el asiento de la misión por 7 años y donde ha permanecido y queda un grupo organizado, que ha resistido los embates de "los años solos y sin experiencia", "bautizadores", y "maestros de toda suerte", mantienen un local de predicación, testifican en la calle en castellano y en quechua, cooperan en el culto en todo sentido. ${ }^{14}$

Se trata de una fuerte competencia religiosa entre pentecostales y protestantes. Pero esa animadversión es una historia que viene desde Chile, dado que los pentecostales fueron expulsados del seno metodista, malestar que permaneció por mucho tiempo. Pero las estrategias simbólicas y sociales de los pentecostales son eficientes, en tanto, "el hombre depende de símbolos y de sistemas de símbolos, y esa dependencia es tan grande que resulta decisiva para que el hombre sea una criatura viable" (Geertz, 2003, p. 96), generando crisis. Si ello no se resuelve, aunque sea simbólicamente, se buscan otros universos de sentido, y es ahí donde la búsqueda de respuesta se encuentra en los sueños y visiones, algo que los pentecostales le asignan gran valor como recurso de revelación.

13 Fuego de Pentecostés, 1951, núm. 267, pp. 12-13.

14 Fuego de Pentecostés, 1951, núm. 267, pp. 12-13. 


\section{SUEÑOS Y VISIONES}

Los pentecostales van a integrar y ofrecer recursos coherentes con la cosmovisión indígena, tales como los sueños y las visiones, recursos culturales importantes para las comunidades receptoras. Estos elementos fueron identificados en otras investigaciones varias décadas más tarde y en otros contextos de América Latina (Foerster, 1989; Muratorio, 1982). Los sueños y las visiones cumplen una función central entre los indígenas y los pentecostales (Andrade, 2004; Garma, 1987; Guerrero, 1994; Miller, 1979). He aquí un relato:

Una noche tuve una visión en el mismo templo, durante la reunión, era en forma de un pescado negro, muy grande, de un color totalmente negro con una cola también negra y larga, que salió del centro de la Iglesia y con la cola casi me dio un ramalazo, yo clamaba al Señor con todo mi corazón, y al fin salió ese monstruo por el techo. Y así desapareció la visión. Luego se manifestó el Espíritu del Señor, una hermana fue tomada en llanto y gritos y se levantó a pedirle perdón a todos y al mismo tiempo una niña de 10 años fue tomada del mismo espíritu, y llorando clamaba que la perdonaran todos los hermanos [...] En ese instante el hermano Alva rompió en llanto, la hermana Agustina por otro lado impulsada del mismo espíritu pedía perdón a su esposo... A los pocos días nos han criticado las otras misiones, diciendo que damos gusto a la carne, pero con estas manifestaciones ha empezado para nuestra patria las primeras gotas de esa lluvia gloriosa que es el derramamiento del Espíritu Santo. ${ }^{15}$

Esta narrativa es puesta como un relato de origen del pentecostalismo en Bolivia. La interpretación del crecimiento y expansión será propicio al mundo indígena: visiones, sueños, oraciones, cultos catárticos, donde participarán hombres y mujeres, adultos y niños. De este modo, se van haciendo diferencias entre la actividad religiosa y la experiencia religiosa (Geertz, 2003), donde, en esta última, los símbolos serán de vital importancia para gestar procesos de resignificación en todos los sentidos, sean religiosos o sociales. Los peces tienen una gran importancia simbólica en el imaginario cristiano, especialmente en el pentecostalismo de estos años, cuyos conversos venían del mundo agromarítimo. Por tanto, soñar con peces es símbolo de resurrección y fertilidad, pero si es negro, representa una liberación de aquello que

15 Fuego de Pentecostés, 1953, núm. 290, p. 13. 
impide dicho éxito. Por otro lado, el relato también da cuenta de los conflictos que los cultos pentecostales producen, por su carácter exático y catártico, lo cual generaba vergüenza al protestantismo misionero vinculado a la razón y las emociones controladas.

No obstante, lo que era rechazable para el protestantismo, fue atractivo para los conversos indígenas, ya que "la centralidad de la religión no está en solucionar problemas, sino en brindar los recursos simbólicos para hacerlos más tolerables, soportables y sufribles" (Geertz, 2003, p. 100). Y en esto el pentecostalismo fue efectivo, ya que en sus cultos los indígenas encontraron la libertad para expresar sus emociones y sentimientos al llorar, gritar y cantar, y experimentar la liberación, aunque sea por momentos, de años de opresión. Grupos como los campesinos, indígenas y subproletariados tenían la posibilidad de liberarse emocionalmente por la vida dramática que les ha tocado vivir, por los años de injusticia y miseria social. Todos esos sentimientos trágicos podían ser liberados en el culto pentecostal, sin temor ni vergüenza, pues las manifestaciones eran atribuidas a la acción del Espíritu Santo.

El pentecostalismo, como toda tradición religiosa, "afirma enérgicamente la proposición de que la vida hiere, lastima” (Geertz, 2003, p. 99) y, por tanto, promueve la búsqueda de esos tiempos y espacios catárticos para la liberación emocional, para luego levantarse y enfrentarse a la cruda realidad, aunque esta no haya cambiado en la vida cotidiana. Pero, sí ha cambiado la realidad interna del individuo y puede mirar la situación sin embozo. Las manifestaciones de los sueños, oraciones, visiones y cultos catárticos comenzaron a brindar frutos, especialmente con el pastor Salguero, de origen boliviano y conocedor del idioma quechua, "nos está bendiciendo el Señor en este nuevo local, he mandado hacer otras bancas porque ya las 10 bancas con que cuenta nuestro local ya están llenas" ${ }^{16}$ Con los líderes bolivianos y el uso de la lengua, pero además la prédica y los mensajes divinos insertos en la cosmovisión andina, los pentecostales comienza a despegar dos décadas después, tal como lo señalara Riviere (2007).

Fue un crecimiento lento, "hemos comenzado el año 1954 con novedades, tres nuevos hermanos nos han dado el bendito Espíritu y también la Escuela Dominical ha crecido". ${ }^{17}$ La Escuela Dominical, una estrategia pedagógica que nació en un contexto urbano y proletario en la Inglaterra del siglo

\footnotetext{
${ }_{16}$ Fuego de Pentecostés, 1953, núm. 290, p. 13.

17 Fuego de Pentecostés, 1954, núm. 297, p. 14.
} 
XVII, cumplía una doble función: alfabetización y socialización religiosa. Los pentecostales, además, añadieron el otorgamiento de comida a estas escuelas informales, dado que asistían niños pobres. Esto ayudó a muchos indígenas a aprender a leer y escribir, inspirados en la motivación de que el Espíritu Santo los ayudaría y los capacitaría para el aprendizaje, porque Dios así lo quería, para que las personas leyeran individual y comunitariamente la Biblia. Cualquiera que sea, "el papel que desempeñe la intervención divina en la creación de la fe, primariamente, por lo menos la convicción religiosa, aparece en el plano humano partiendo del contexto de actos concretos de observancia religiosa (Geertz, 2003, p. 107).

Todo tiempo, lugar y ocasión significaba una posibilidad de conversión, predicación, culto o para levantar una pequeña congregación. Por ello, para un pastor no importaba cuántos kilómetros podía viajar para ganar o atender a una sola persona, ya que dicho individuo tenía mayor prioridad que su familia, vecinos y conocidos. No era el presente lo que importaba al pentecostalismo, sino el futuro: el porvenir de una nueva congregación,

Visité la ciudad de Juliaca, aquí viven 2 familias de nuestra Iglesia que se trasladaron de La Paz (Bolivia) [...] Visité también el pueblo de Conima, situado en los alrededores del "Lago Titicaca", donde tuve la oportunidad de celebrar tres reuniones [...] En seguida seguí el viaje al Puerto de Puno. Conviene hacer notar que todos estos pueblos son de habla Aymará, pero gracias a Dios que no tuve dificultad alguna con el dialecto. ${ }^{18}$

El dolor, la enfermedad, todas eran posibilidades para predicar y orar por sanidad. Un pastor podía ayunar, arrodillarse y orar por horas o todas las noches. No era la sanidad lo que finalmente hacía que el enfermo se convirtiera o sanara, aunque la sanidad también influía en la conversión, sino la preocupación de alguien desconocido por su vida, tal como lo muestra el relato que sigue, "fuimos con un hermano a las Yungas [...] llevamos el mensaje de salvación, repartimos tratados y nos gozamos en las reuniones de la noche [...] habían hermanos enfermos, los ungíamos en el nombre del Señor y alcanzaban sanidad". ${ }^{19}$

${ }_{18}$ Fuego de Pentecostés, 1961, núm. 378, p. 5.

19 Fuego de Pentecostés, 1961, núm. 378, p. 5. 


\section{ENFERMEDAD Y SANIDAD}

En el caso de las enfermedades, se inserta el dolor dentro de un universo de sentido significativo, "efecto reconfortante que estriba en última instancia en poder dar a la persona enferma un vocabulario que le permita comprender la naturaleza de su mal y referirla a un mundo más amplio" (Geertz, 2003, p. 101). Dado que la enfermedad y el dolor generan dramas individuales, familiares y sociales, la "dramatización permite el abandono de la pasividad y la reafirmación de que es posible a cada uno intervenir en la vida cotidiana" (Silveira, 2000, p. 58). Más aún cuando la interpretación que hacen los pentecostales sobre la enfermedad y la sanidad, tiene vínculos estrechos con la tradición cultural (Garma, 1985; Guevara, 2009), y más aún cuando dicha concepción se trata de una cosmovisión dualista que concibe el mundo como un espacio de confrontación de fuerzas positivas y negativas (Moulian, 2005, 2008).

Cada vez los lugares de prédicas se hacen más lejanos, y debido a las distancias, los pentecostales van insertando otras estrategias para predicar, como es el caso del uso de la bicicleta, "el Cuerpo de Ciclistas [...] Que por ningún motivo se deshagan de sus rápidos caballitos [...] De esta manera serán siempre fieles ayudadores de sus Pastores y del crecimiento de la Obra". ${ }^{20}$ De este modo, los pentecostales siguen la tradición católica cuasimodista, no sólo de atraer a la gente a la iglesia, sino llevar la iglesia a la gente, sobre todo a los espacios rurales. Lo innovador es que los pentecostales no lo hacen sólo por Semana Santa, sino todos los fines de semana, buscando a la gente en sus espacios laborales, sobre todo a los enfermos. De este modo, la práctica religiosa pentecostal logra traslaparse con la cosmovisión andina, materializando el origen del mal en el diablo. La solución es la conversión, y la terapia es el acompañamiento, con el objetivo de que el paciente logre captar nuevos conversos como recurso para recuperación y sanidad. De ese modo, el llamado "problema del mal es la verdadera naturaleza de las fuerzas destructivas que moran en la persona y fuera de él" (Geertz, 2003, p. 121). Por lo tanto, la única forma de superación es el acompañamiento.

Los pentecostales logran captar de la cosmovisión indígena la necesidad de acercar o no separar lo sagrado de lo profano. Para ello, llevaron la prédica, "aun a los interiores de los mercados". ${ }^{11}$ De este modo la religión se

20 Fuego de Pentecostés, 1940, núm. 135, p. 9.

${ }^{21}$ Fuego de Pentecostés, 1940, núm. 145, p. 6. 
acerca al trabajo, algo que es muy propicio para las comunidades andinas, cuyo centro son los mercados. El hecho de que los pentecostales acerquen la iglesia al mercado les brindó oportunidad para que las personas pudieran conocerlos, "una mañana al salir de misa yo y mi familia bajamos por el mercado Campero; entonces oí la palabra por el predicador evangélico [...] Y así llegué a la Iglesia Pentecostal [...] en Junio de 1941 [...] aprendí a leer leyendo la Biblia, para servirle en su viña y trabajar sólo para Él”. ${ }^{22}$ De este modo, el pentecostalismo mostraba mayor eficiencia que el catolicismo en la oferta y administración del sentido y el problema del mal.

La estrategia más significativa fue llevar la oferta de sanidad al mercado y a las calles, sacralizando los espacios profanos, y de ese modo mantener a raya el problema del mal, y así generar en la conciencia de los conversos un reencuentro entre el problema del bien y el mal (Geertz, 2003). Pero dicha solución de sentido no implica, necesariamente conversión:

El Señor ha acompañado con prodigios y milagros de sanidades. En la unción por la fe, el Señor ha sanado a varias personas de diferentes enfermedades, pero por desgracia, se han conducido como los nueve leprosos que no volvieron a dar gracias al Señor. A una de ellas el médico le había calculado 4 días de vida, recibió la unción por la fe, y el día antes de vencerse el plazo fijado, fue sanado por el Señor. ${ }^{23}$

Pese a orar por los enfermos y ser estos sanados, no se trataba de un intercambio simbólico de oración y terapia o enfermedad y sanidad a cambio de conversión, lo que resultaba en un intercambio de un don fallido como se aprecia en la cita anterior. No obstante, ya se había inscrito como opción simbólica eficiente. Dicha dinámica entre sanidad y conversión no era entendida de la misma manera por los indígenas como esperaban los pentecostales. Por lo tanto, se entiende lo religioso como un servicio civil más que una conversión. Es la oración y la imposición de manos para sanar a los enfermos permite al pentecostalismo, paulatinamente, constituirse en una oferta religiosa distintiva,

${ }^{22}$ Fuego de Pentecostés, 1951, núm. 267, pp. 12-13.

${ }^{23}$ Fuego de Pentecostés, 1940, núm. 145, p. 6. 
Oremos para que Bolivia sea para Cristo, y le comunico que la dueña de casa donde vivo se está convirtiendo al Señor y Él está haciendo la obra. Estaba enferma y va sanando; a Él sea la honra y gloria, y ella pide a todos los hermanos chilenos que ayuden en oración para que se conviertan sus cinco hijos y cinco hijas. Estamos trabajando mucho para el Señor. Su visita a Bolivia ha sido bendición. ${ }^{24}$

La oferta pentecostal se va afianzando de manera significativa pues, por un lado, ofrece terapia de sanación y acompañamiento, pero por otro, también se transforma en un canal a través del cual la persona misma interpreta su situación y condición existencial. Como dice Geertz (2003), "hay por lo menos tres puntos en los que el caos amenaza irrumpir en el hombre: en los límites de su capacidad analítica, en los límites de su fuerza de resistencia y en los límites de su visión moral" (p. 97). En este sentido, el pentecostalismo ofrece un horizonte de sentido coherente con la cosmovisión andina.

Los pentecostales también tienen que luchar con los mitos que se construyen sobre las minorías religiosas,

Oía decir que al pueblo venían los masones, que comían a las gentes, por lo cual les tenía miedo, buscaba la manera de no encontrarme con ellos. Más tarde cuando salí de la casa de mis tíos; trabajé en la casa de protestante; así lo llamaban al predicador cristiano. Ellos oraban y cantaban, pero yo no llegué a comprender el verdadero significado, aunque también cantaba y oraba con ellos, pero lo hacía, por deber nada más. Un día vino una amiga y me insinuó acompañarle a la chichería donde habíamos bebido algunas copas de chicha, cuando llegué a mi trabajo, el predicador me echó de la casa diciéndome que era borracha. ${ }^{25}$

En el relato aparecen los mitos urbanos en relación con los protestantes, que encontramos en casi toda América Latina, quienes eran considerados masones, "comegentes" o "que pisotean el rostro de las vírgenes católicas", imaginarios que también se extendieron al judaísmo y al comunismo.

Se resalta el carácter puritano y ascético del protestantismo, intolerante frente a cuestiones morales tales como el consumo de bebidas alcohólicas,

${ }^{24}$ Fuego de Pentecostés, 1951, núm. 267, pp. 12-13.

25 Fuego de Pentecostés, 1951, núm. 267, pp. 12-13. 
aunque los pentecostales abordaban dicha problemática de una forma mucho más positiva. Para un protestante, un alcohólico era un vicioso. Para un pentecostal, representaba una persona enferma que necesitaba ser sanado y liberado por el Espíritu Santo. Para los pentecostales el alcoholismo no era un problema individual, sino espiritual: el diablo era el que llevaba a una persona a beber. Esto implica que, "el problema del mal es la idoneidad de los recursos simbólicos para suministrar una serie viable de criterios éticos, de guías normativas que gobiernen nuestras acciones" (Geertz, 2003, p. 102). Por tanto, si el borracho se convertía al pentecostalismo, se le acompañaba, y si tenía alguna recaída, la responsabilidad no era de él, sino del diablo; esto hacía más tolerable su acompañamiento.

\section{REDEFINICIÓN DE LA COMUNIDAD Y CONSTRUCCIÓN DE REDES MISIONALES}

Los investigadores pioneros destacaron que el crecimiento pentecostal se debía a que este grupo religioso funcionaba a partir de un fuerte sentido de lazo comunitario (D’Epinay, 1968; Kessler, 1967; Willems, 1967; Foerster, 1989). Esta característica se observa en la Iglesia Evangélica Pentecostal (IEP) ${ }^{26}$ en las redes comunitarias, oscilando entre lo transversal y lo longitudinal, desde Santiago a Valparaíso, luego a la Serena hasta Antofagasta pasando por Calama; y desde aquí a ciudades y pueblos bolivianos. Cuando un pastor viajaba,

${ }^{26}$ La Iglesia Evangélica Pentecostal tiene un tronco común con la Iglesia Metodista Pentecostal, nacida luego del avivamiento de 1909 y que se constituye como iglesia en abril de 1910 dirigida por Willis Hoover. Desde un comienzo publicaron una revista institucional con una regularidad mensual, que venía de un laico presbiteriano, llamada Chile Evangélico y que al ser admirador del movimiento pentecostal se transformó en el gran difusor del movimiento, y por ese motivo la revista pasa a la administración de la Iglesia Metodista Pentecostal en el año 1910 con el nombre de Chile Pentecostal. Sin embargo, Willis Hoover cambia el nombre de la revista a Fuego de Pentecostés en el año 1928. En el año 1932 se produce un cisma, producto de una lucha nacionalista, ya que Hoover era estadunidense, pero que en realidad se trató de una lucha de poderes por dirigir el movimiento pentecostal. Fue inevitable el cisma, de donde se separa el pastor Manuel Umaña quedando con el nombre de la Iglesia Metodista Pentecostal y retoman el nombre de la revista Chile Pentecostal, y el grupo de pastores que quedó apoyando a Hoover pasan a llamarse Iglesia Evangélica Pentecostal, que continúan la revista Fuego de Pentecostés. Gracias a esta competencia por el carisma, ambas iglesia lograron crecer y permanecer, sin evitar permanentemente pequeños cismas, pero hasta hoy son las dos denominaciones más grandes de Chile y las representaciones sociales que hay sobre los pentecostales están referidos a ellos. 
se va deteniendo de lugar en lugar. En el caso del espacio andino, aprovecha las redes y caminos que han transitado los aymaras desde sus mismos ancestros: "Salimos de Antofagasta, el que escribe y el Pastor Tomás López, el viernes 3 de agosto por tren hasta Oruro, él fue el asiento de la misión del Pastor Manuel González que regresó a Chile. Allí nos esperaba el Pastor Daniel Salguero, vino a encontrarnos desde La Paz, el cual nos acompañó desde allí en toda nuestra estadía en el vecino país, bajamos por el norte, por Arica." ${ }^{27}$

La IEP hace usos de estas redes ondulatorias, tanto del lado chileno como del lado de Bolivia y así va aflorando el esfuerzo misionero, haciendo uso de las redes comunitarias:

El 2 de marzo de 1958, el Señor nos concedió la oportunidad de un nuevo local en la ciudad de La Paz (Bolivia), con la asistencia de los pastores Daniel Salguero de La Paz, el pastor Manuel Vera de la ciudad de Cochabamba y Luis Orellana de esta Iglesia [...] Hicimos un almuerzo a la chilena, a las dos de la tarde la consagración donde asistieron 100 personas, y después de esta reunión tuvimos un desfile en la calle. La reunión de la noche se efectuaron casamientos y bautizos [...] en Bolivia hay amplia libertad de culto. ${ }^{28}$

Se debe hacer una diferencia entre los pastores que dirigen una iglesia y los "encargados de obras": los primeros son chilenos y los segundos bolivianos. De igual modo, los primeros eran extranjeros y migrantes, $y$, como tales, siempre mantienen una añoranza por su país de origen. Saben que en cualquier momento dejarán Bolivia, por tanto una forma de volver al país es a través de la comida, una de las formas más comunes de canalizar dicha nostalgia. Así, la construcción de redes comunitarias entre pastores chilenos era una necesidad fundamental. De este modo, las iglesias dirigidas por pastores eran centros neurálgicos de misiones a otros barrios y pueblos cercanos:

Salimos de la ciudad de La Paz, en una gira misionera pedestre con destino al pueblo de Laja que dista $42 \mathrm{kms}$ [...] nos fuimos a dicha región a predicar la palabra de Dios a los habitantes de habla aymará [...] para llegar al pueblo ya mencionado, entramos a la casa de una familia nativa para hablarles de nuestro Señor Jesucristo, luego de hablarles de este Cristo, que salva y compun-

27 Fuego de Pentecostés, 1951, núm. 267, pp. 12-13.

${ }^{28}$ Fuego de Pentecostés, 1958, núm. 348, p. 17. 
gidos de corazón oraron con nosotros y nos ofrecieron comida [...], después de esta bendición y de este trabajo nos despedimos de esta familia, y cuando continuábamos nuestra caminata el padre de familia de la ya mencionada casa nos salió al encuentro en su bicicleta y nos ofreció su casa para alojarnos en la noche [...] ya llegados al pueblo empezamos el trabajo de predicación con el sistema Pentecostal de predicación casa por casa y esquina por esquina, tuvo éxito este trabajo porque muchas personas salieron de sus hogares para oír las buenas nuevas de salvación en cuanto al de dialecto aymará no tuvimos dificultad alguna, porque el Señor llevaba entre los jóvenes un buen interprete, de tal suerte que todos predicamos, hasta el pastor chileno. ${ }^{29}$

El hecho de que los pentecostales vayan de pueblo en pueblo, de lugar en lugar a predicar, y que sean recibidos, es justamente por el valor que los andinos otorgan el escuchar las prédicas en su lengua nativa. Esto admite encontrar simpatizantes y nuevas conversiones, y por su puesto un conjunto de redes de casas que, a su vez, les permitirá alcanzar a otros lugares y personas. De igual modo, los pentecostales se ven beneficiados por la reciprocidad y gentileza aymara: al recibirles, sienten la necesidad de retribuir, y lo hacen no sólo con comida, sino también con alojamientos.

El superintendente, pastor Morgues, quien fue migrante (misionero y obrero) por 19 años en Argentina, incentivará las misiones, pero también la relevancia de las redes comunitarias para los viajes y visitas misioneras, y de este modo acompañar y motivar sus misioneros en Bolivia,

Nos dirigimos a La Paz, acompañados por el Pastor Vera, el Pastor Salguero y familia nos recibió con mucho gozo; estuvimos con ellos trabajándole al Señor... hasta La Paz tuvimos la dicha de ser acompañados por el Pastor Vera, donde quedó muy agradecido por nuestra visita, donde vio que el Señor no lo habían dejado sus hermanos chilenos, que siempre estarán orando por esos campos. $^{30}$

En el año 1958, el superintendente Morgues envía un nuevo misionero a Bolivia, en este caso en la ciudad de Oruro, donde hubo varios intentos de trabajo misional, pero sin resultados exitosos,

${ }^{29}$ Fuego de Pentecostés, 1958, núm. 348, p. 18.

30 Fuego de Pentecostés, 1957, núm. 338, p. 12. 
Por segunda vez el Señor me concede la posibilidad de visitar Bolivia, cumpliendo un encargo de nuestra conferencia recién celebrada en Osorno, de ir a dejar al Pastor probando Carlos Rodríguez P., a Oruro (Bolivia). Después de preparar el viaje y los documentos necesarios, nos juntamos en Antofagasta, el Pastor Rodríguez, su esposa y dos hijos de 12 y 15 años [...] Estuvimos algunos días en la Iglesia de Antofagasta, donde fuimos atendidos como hijos del Rey. ${ }^{31}$

Estos viajes permitían visitar iglesias y congregaciones nacionales y locales en el camino, de donde se levantaban ofrendas para ayudar a los nuevos misioneros, que viajaban con su familia. Así lo muestra este relato,

Salimos de Antofagasta en tren hacia Oruro, llegando al día siguiente a las $10 \frac{1}{2}$ de la mañana, nos esperaban los pastores, Salguero, Orellana y varios hermanos de la Iglesia de Oruro, en la tarde llegó el pastor Manuel Vera de Cochabamba. En la reunión de la noche y en presencia de 5 pastores fue presentado el Pastor Rodríguez [...] en esa noche habían más de 50 personas, todos contentos y alegres y hasta cantaron en su dialecto. ${ }^{32}$

Como señalamos anteriormente, el hecho de que en esta primera etapa los pastores de iglesias pentecostales en Bolivia sean chilenos, permite que entre ellos construyan una mayor cercanía comunitaria, lo que se transmite a las iglesias. Las visitas misioneras, y su posterior reporte de iglesia en iglesia, tienen, según Geertz (2003), "la finalidad de dar una imagen específica y concreta de verdadero sufrimiento humano" (p. 101), según lo concebían los pentecostales. Y este sufrimiento, cuyo modelo está encarnado en el misionero y su familia, permite la sensibilización para que distintos creyentes contribuyan con dinero para misiones. Pero, además, los viajes eran aprovechados por los dirigentes de la IEP, para conocer congregaciones y otras pequeñas comunidades religiosas que había en distintos poblados, tanto del norte de Chile como de Bolivia,

Viajamos a Sacaba donde está ubicado el pastor Vera, esta iglesia tiene un grupito Quillacoyo, Parotani y Sacaba [...] gracias al Señor hay algunos frutos. Visitamos todos esos pueblos, predicamos al aire libre, celebramos varias reu-

${ }^{31}$ Fuego de Pentecostés, 1958, núm. 346, p. 18.

32 Fuego de Pentecostés, 1958, núm. 346, p. 18. 
niones, se recibieron algunos probandos, en Plena Comunión y Bautismos [...] la gente tiene hambre de las cosas de Dios, se esperan muchos frutos [...] salimos para La Paz, estuvimos con el pastor Salguero en La Paz, nuevo gozo, más tarde con el pastor Orellana, ese día en la noche tuvimos reunión en la Iglesia del pastor Orellana en Villa San Antonio, asistieron más de 30 personas... un local cedido por un hermano en barrio Caiconi. J. Gómez y A. Fernández. Pastores chilenos. ${ }^{33}$

Uno de los aspectos destacado por los pastores pentecostales chilenos de los andinos bolivianos es su solidaridad, generosidad que manifiestan, especialmente con el forastero y que se aparecía en los relatos. De tal manera, el pentecostal aymara y también el quechua se constituye en una comunidad dentro de la comunidad aymara (Tudela, 1993). El relato destaca: "al otro día un hombre de habla aymara nos invitó a su casa para que le habláramos a su familia de la Palabra de Dios, tuvimos la dicha de caminar $5 \mathrm{kms}$, hasta su hogar donde nos gozamos de haber conocido otra familia, ellos están dispuestos a servir al Señor". ${ }^{34}$ Dado que estas zonas estaban apartadas, los sacerdotes católicos no iban a esos lugares. Es por ello que se valora de manera particular la labor misionera pentecostal. Más bien, se trata de una valoración mutua: los aymaras valoran la predica en su idioma y ellos responde con generosidad y reciprocidad, "Señor nos use como él quiera y así seremos buenos soldados y eficientes instrumentos en las manos del Señor [...] con estas hermosas cualidades de un verdadero obrero de los campos del señor, podremos apreciar el valor de imperioso llamado de Jesús a sus verdaderos discípulos. 'Alzad vuestros ojos, y mirad las regiones, porque ya están blancas para la siega."”35

Entre los aymara se valora el uso de las metáforas desde militares a metáforas agrícolas. Hay otros elementos que son coincidentes entre pentecostalismo y mundo indígena, es el uso de metáforas climatológicas porque se trataba de un pentecostalismo chileno con notable influencia rural y campesina, "hemos recibido del Pastor Salguero que son como el agua fría al alma sedienta, así son las buenas nuevas de lejanas tierras". ${ }^{36}$

\footnotetext{
33 Fuego de Pentecostés, 1958, núm. 346, p. 18.

34 Fuego de Pentecostés, 1958, núm. 346, p. 18.

35 Fuego de Pentecostés, 1958, núm. 346, p. 18.

36 Fuego de Pentecostés, 1953, núm. 290, p. 13.
} 
De igual modo, en Oruro el pentecostalismo de origen chileno va creciendo por esta época, "en Oruro [...] al pastor Rodríguez le fueron impuestas las manos y quedó como un diácono en nuestra Iglesia. En esa ocasión se recibieron 10 miembros como probando, hubo un casamiento, bautismos y dos en plena comunión". ${ }^{37}$ Estas narraciones muestran que no se perciben sentimientos antichilenos de militares, políticos, o de la población en general. Los actos de violencia están más relacionados con las respuestas a la prédica pentecostal, que también es de alguna manera violenta.

Justamente estas inestabilidades políticas y el efecto que tiene en las comunidades aymaras ayudan a convertirse al pentecostalismo, "Bolivia ha estado en estado de sitio por algunos disturbios políticos, pero nosotros con todo eso pudimos gozar de reuniones que en Cochabamba hubo que alargarlas hasta las once".$^{38}$ Según Tudela, quien destaca que el cambio religioso propuesto por los pentecostales y aceptado por la comunidad aymara, es reflejo de un cambio y un conflicto ideológico (Tudela, 1993).

\section{RITOS Y CEREMONIAS}

El pentecostalismo no habría tenido arraigo en la cultura andina con un sistema simbólico incoherente con la cultura (Geertz, 2003, p. 107). Este enraizamiento no es pacífico ni armónico, sino conflictivo, pues los sujetos no reciben los nuevos símbolos ni aceptan las nuevas ritualidades de una manera pasiva. Así como la cultura y las religiones, también los individuos son marcados por luchas entre tradiciones simbólicas heredadas y adquiridas. Este es un proceso fuertemente conflictivo. No obstante, el carácter simbólico de los fenómenos culturales se inserta siempre en contextos y procesos históricamente específicos (Thompson, 1998, p. 203).

El pentecostalismo tuvo problemas con el protestantismo porque estos últimos siempre acusaban a los pentecostales por sus cultos catárticos. Se trataba de una diferencia en términos de configuración ritual, especialmente de los espacios litúrgicos. Para los protestantes, los cultos bulliciosos y descontrolados de los pentecostales eran causantes de que las personas discriminaran o estigmatizaran a todos los evangélicos,

37 Fuego de Pentecostés, 1958, núm. 349, p. 15.
${ }_{38}$ Fuego de Pentecostés, 1958, núm. 349, p. 15. 
Tuvimos el gozo de llegar a la casa del Pastor Manuel Vera... donde nos reunimos desde el jueves 11 hasta el domingo 14, en la localidad de Sacaba (соснABAMBA). Las reuniones eran concurridas por unas 15 a 18 personas [...] Pese a las dificultades que este siervo del Señor tuvo al principio, pero Dios está obrando y llamando a las almas a su redil, las dificultades ya están pasando; pero ahora se está presentando la dificultad de la persecución que le hacen otras denominaciones. ${ }^{39}$

Los ritos pentecostales como la prédica en la calle, los cultos catárticos, el desborde de emociones en público (inclusive en la calle), las vigilias extensas y bulliciosas, generaban muchas veces malestar entre los vecinos. De igual modo, los protestantes criticaban a los pentecostales por considerar que ellos levantaban espacios cúlticos cerca de sus templos, o bien se "robaban" su feligresía. Por otro lado, los pentecostales también predicaban contra el protestantismo por considerar sus ritos cúlticos fríos y sin espíritu. El siguiente relato da cuenta del tipo de configuración carismática y emotiva de los cultos pentecostales:

El señor se manifestó en la oración de la noche, cuando todos los santos estamos reunidos en ferviente clamor y alabanzas delante de su presencia... Estábamos orando los hermanos... Mientras clamábamos en espíritu el hermano Lucio comenzó a saltar desde un lugar a otro y lo tuvo largo rato sin conocimiento, pero consciente del Señor, hasta terminar la oración no abrimos la puerta porque el Señor estaba con su bendita presencia entre nosotros [...] También tomó a mi Luzmila y al hermano René Álvarez y muchos curiosos se juntaron a las puertas y cuando se levantaron fue abierta la puerta, aunque algunos golpeaban que se les abriera. ${ }^{40}$

Pero los pentecostales no consideraban que sus ritos cúlticos sean bulliciosos o desordenados, sino que decían que "donde está el Espíritu de Dios: ahí hay libertad", la cual se manifestaba de diversas maneras, especialmente notorias y emotivas. Incluso esta afirmación bíblica no sólo era un eslogan, sino también un canto. De igual modo existía otra frase que decía: "los hombres sabemos a qué hora comienza el culto pero sólo ese Espíritu sabe a qué

39 Fuego de Pentecostés, 1957, núm. 338, p. 12.

40 Fuego de Pentecostés, 1954, núm. 297, p. 14. 
hora termina". Esto daba lugar a la libertad emocional y la extensión del culto hasta medianoche. Se trata de "una forma ritual, donde los estados anímicos y motivaciones que los símbolos sagrados suscitan en los hombres y donde las concepciones generales del orden de la existencia que ellos formulan para los hombres se encuentran y se refuerzan los unos a los otros" (Geertz, 2003, p. 107).

A medida que la IEP comienza a extenderse hacia zonas rurales y campesinas, adentrándose más al territorio aymara, los conflictos con los protestantes van disminuyendo. No obstante, ello no significaba que se le hiciera más fácil, sino que aún existía un rechazo a la nueva religión por considerarse extraña y extranjera. Estas experiencias de persecución y discriminación son útiles para que el pentecostalismo reformule su mito fundacional en Bolivia, "el hermano Valencia tuvo en Sacaba la bendición de recibir algunos puntapiés y le hicieron pedazos los tratados que repartió y se los tiraron a la cara. El Pastor está visitando una familia en Mollimolle, a unos 2 kilómetros de Sacaba; también tiene una familia en Quillacoyo; es un pueblo que está a 25 kilómetros de Sacaba." ${ }^{41}$

De esta manera, a fines de la década de 1950 el pentecostalismo chileno se adentraba más al mundo andino, sobre todo a los espacios rurales, fundamentalmente en aquellos lugares donde prácticamente ni el catolicismo ni el protestantismo había llegado,

Con el Pastor Vera nos dirigimos el día 15 a Cochabamba, y en la noche celebramos una reunión en la casa del hermano García; el martes 16, en la mañana, nos dirigimos con el Pastor Vera a Parotani, a unos 52 kilómetros de Sacaba; allí el Pastor Vera tiene unos 10 hermanos, sin contar los niños, en ese lugar se efectuaron reuniones; martes en la noche y el miércoles 17; después que terminaba la reunión los hermanos se quedaban más de una hora cantando con nosotros al Señor. ${ }^{42}$

Lo significativo es que personas del mundo indígena no sólo se convertían, sino que además prestaban sus casas o bien donaban un lugar para realizar cultos pentecostales o levantar templos. Estos espacios se transformaban en instancias cúlticas, pero también de oraciones intercesoras y de ayunos, a

${ }^{41}$ Fuego de Pentecostés, 1957, núm. 338, p. 12.

42 Fuego de Pentecostés, 1957, núm. 338, p. 12. 
veces en casa u otras en el desierto, el "flamígero coraje consiste en aquellas propensiones a ayunar en el desierto, a realizar solitarias incursiones al campamento enemigo y a estremecerse pensando en dar algún golpe maestro" (Geertz, 2003, p. 94), en este caso ganar familias y comunidades indígenas completas, y para ello había que combatir con el mal a través del ayuno, la oración y las vigilias.

Otras de las ritualidades muy significativas de los pentecostales para los nuevos líderes locales aymara fueron las conferencias locales, regionales, nacionales e internacionales. Dichos eventos representaban una posibilidad de reubicación y dignificación social para aquellos pastores que venían de contextos de marginación por ser indígenas, campesinos, obreros o, a veces, por tener historias de vida sumidas en problemáticas con el alcohol, la violencia y el abandono, en el caso de los varones. En estos eventos había que llegar bien vestidos, lo que para la época significaba ascenso social. Por ello puede parecer que el pentecostalismo inducía a los indígenas a abandonar sus vestimentas indígenas, pero ellas eran también el símbolo del desprecio y de la ignominia en las ciudades. Por lo tanto, el traje pentecostal era símbolo de honorabilidad, honra y de ascenso social, por lo menos para el tiempo de asistir a conferencias en las ciudades.

Estos encuentros significaban también la posibilidad de contar sus testimonios: el acceso a la palabra y ser escuchados. Cuanto más dramático y trágico era el testimonio, más honrado y legitimado era entre los pares pentecostales. Ahí no importaba tanto la dimensión del templo, por lo menos no todavía, sino con cuánto sudor, discriminación, dolor, oraciones y ayuno había costado levantarlo, según los relatos testimoniales que compartían. Es por ello que un pastor pentecostal no quedaba tranquilo con una pequeña congregación, sino que debía abrir varias:

Con fecha 19 de diciembre de 1959, el Señor nos concedió la oportunidad de viajar a la amada República de Chile, en compañía de mi esposa para asistir a las Conferencias [...] El Señor me habló por su Espíritu Santo que llegando a mi regreso a Bolivia me esperaba una bendición [...] Una vez que llegué de Chile visité parte de nuestro campo en Moho (Perú) y el día domingo 31 de julio del presente año (1960) tuve la oportunidad de inaugurar un nuevo local, con una asistencia de unas 37 personas a la Escuela Dominical. ${ }^{43}$

${ }^{43}$ Fuego de Pentecostés, 1961, núm. 378, p. 5. 
El ingreso al pastorado permitía a los obreros religiosos una posibilidad de ascenso social y además la posibilidad de viajar, que si bien es cierto no siempre se contaban con los recursos económicos, sí existían redes para hospedar de lugar en lugar donde hubiese otros pentecostales.

\section{LISTA DE REFERENCIAS}

Alves, R. (1979). Protestantismo e repressão. São Paulo: Ática.

Andrade, S. (2004). El protestantismo indígena. Procesos de conversión religiosa en Chimborazo. Quito: Flacso-Ecuador/Abya-Yala.

D’Epinay, C. (1968). El refugio de las masas. Santiago: Editorial Pacífico.

Foerster, R. (1989). Identidad y pentecostalismo indígena en Chile. Creces, 10(6), 12-18.

Foucault, M. (1996). La vida de los hombres infames. La Plata: Altamira.

García, A. (2009). La visión misionera protestante en Chile a fines del siglo diecinueve: Trumbull y el periódico The Record. Universum (Talca), 24(1), 58-81. DoI: http:// dx.doi.org/10.4067/S0718-23762009000100005

Garma, C. (1985). Conversión y los poderes de curación entre los protestantes totonacas. Iztapalapa, 6(12-13), 39-53.

Garma, C. (1987). Protestantismo en una comunidad totonaca de Puebla. México: Instituto Nacional Indigenista.

Garma, C. y Embriz, A. (1994). Afiliación religiosa en el México indígena de 1990. (manuscrito). México: Instituto Nacional Indigenista.

Geertz, C. (2003). La interpretación de las culturas. Barcelona: Editorial Gedisa.

Guerrero, B. (1994). A Dios rogando... Los pentecostales en la sociedad aymara del Norte Grande de Chile. Ámsterdam: Free University Press.

Guevara, A. (2009). Entre el pastor evangélico y el dirigente indígena: discursos religiosos y políticos en dos "comunidades" mapuche del sur de Chile. Revista Cultura y Religión, III(2), 165-187. Recuperado de https://www.revistaculturayreligion.cl/ index.php/culturayreligion/issue/view/17

Hernández, R. (1994). Identidades colectivas en los márgenes de la nación: etnicidad y cambio religioso entre los mames de Chiapas. Nueva Antropología. Revista de Ciencias Sociales, XIII(45), 83-106.

Hollenweger, W. (1976). El pentecostalismo. Buenos Aires: Editorial La Aurora.

Kessler, J. (1967). A study of the older protestant missions and churches in Peru and Chile. Goes: Oosterbaan \& Le Cointre. 
Mansilla, M., Muñoz, W. y Piñones, C. (2016). El postpentecostalismo. La concepción de los migrantes peruanos y bolivianos evangélicos (quechuas y aymaras) sobre el pentecostalismo chileno. Diálogo Andino, 51, 81-91. Dor: http://dx.doi. org/10.4067/S0719-26812016000300081

Mansilla, M. Muñoz, W. y Orellana, L. (2014). Los dilemas comunitarios y étnicos y religiosos: las investigaciones antropológicas del pentecostalismo aymara y mapuche en Chile (1967-2012). Estudios Atacameños, 49, 153-175. Dor: https://dx.doi. org/10.4067/S0718-10432014000300009

Mansilla, M. y Muñoz, W. (2017a). La dramatización de la cultura: los procesos de conversión evangélica aymara (Chile). Chungará (Arica), 49(2), 241-250. DoI: http://dx.doi.org/10.4067/S0717-73562017005000014

Mansilla, M. y Muñoz, W. (2017b). ¿Evangélicos o aymaras? Dinámicas de las representaciones culturales de los evangélicos aymaras (Chile). Revista Estudios Atacameños, 54, 239-258. Recuperado de https://revistas.ucn.cl/index.php/ estudios-atacamenos/article/view/1720

Mansilla, M, Piñones, C., y Liberona, N. (2018). De la identidad a la pluridentidad. Reelaboraciones identitarias entre pentecostales migrantes peruanos y bolivianos indígenas en Arica e Iquique. Sí Somos Americanos, 18(2), 10-33. DoI: https://dx. doi.org/10.4067/S0719-09482018000200010

Martínez, A. (2006). Historia y antropología a propósito del cuerpo. Gazeta de Antropología, 22(19). Recuperado de http://hdl.handle.net/10481/7091

Miller, E. (1979). Los tobas argentinos. Armonía y disonancia en una sociedad. México: Siglo XXI.

Moulian, R. (2005). Mutaciones, convergencias y paradojas en el lepún y el culto pentecostal. La contraparte de la reflexibilidad ritual. Redes. Com. Revista de Estudios para el Desarrollo Social de la Comunicación, 2, 113-134. Recuperado de http:// revista-redes.hospedagemdesites.ws/index.php/revista-redes/article/view/45

Moulian, R. (2008). Mediaciones rituales y cambio social: desde Ngillatun al culto pentecostal. Un estudio de casos múltiples y contrastes sobre la transformación de las prácticas rituales en comunidades Williche de las comunas de Lago Ranco y Río Bueno (Chile). (Tesis de doctorado). Facultad de Ciencias Políticas y Sociología-Universidad Complutense de Madrid, Madrid, España.

Muratorio, B. (1982). Protestantismo, etnicidad, clase en Chimborazo. En B. Muratorio, Etnicidad, evangelización y protesta en el Ecuador. Una perspectiva antropológica (pp. 71-98). Quito: CIESE.

Piedra, A. (2002). Evangelización protestante en América Latina. Análisis de las razones que justificaron y promovieron la expansión protestante. Quito: CLAI-UBL. 
Piñones, C., Mansilla, M. y Muñoz, W. (2016). "La agarradura me la atiendo en la iglesia”: el diablo como símbolo hegemónico en el pluralismo médico aymara pentecostal. Chungará (Arica), 48(4), 645-656. DoI: https://dx.doi.org/10.4067/ S0717-73562016005000037

Piñones, C., Muñoz, W. y Mansilla, M. (2018). El mal paraje y la mala hora: notas sobre la violencia naturalista hacia el saber médico andino. Salud Colect, 14(2), 211224. DoI: https://doi.org/10.18294/sc.2018.1490

Riviere, G. (2007). Bolivia: el pentecostalismo en la sociedad aimara del Altiplano. Nuevo Mundo Mundos Nuevos. Recuperado de https://journals.openedition.org/ nuevomundo/6661?lang=es

Silveira, L. (2000). Teatro, templo y mercado. Comunicación y marketing de los nuevos pentecostales en América Latina. Quito: Abya Yala.

Sthal, F. (1920). Land of the Incas. California: Pacific Press.

Tamagno, L. (2007). Religión y procesos de movilidad étnica. La Iglesia Evangélica Unida, expresión sociocultural del pueblo toba en Argentina. Revista Iztapalapa, 28(62-63), 69-99. Recuperado de https://revistaiztapalapa.izt.uam.mx/index. $\mathrm{php} / \mathrm{izt} /$ article/view/319

Terán, B. (2005). Lo que cuentan los tobas. Buenos Aires: Ediciones del Sol.

Thompson, J. (1998). Ideología y cultura moderna. Teoría crítica social en la era de la comunicación de masas. México: Ediciones UAM.

Tudela, P. (1993). Cambios religiosos y revitalización de la comunidad entre los aymaras de Arica 1960-1990. Nutram, Ix(33), 15-48.

Valenzuela Arms, R. (2000). Historia de la Iglesia metodista de Chile (1078-1903). Santiago de Chile: Iglesia Metodista.

Willems, E. (1967). Followers of the new faith, cultural change and the rise of protestantism in Brasil and Chile. Nashville: TN, Vanderbilt University Press. 